\title{
Low level diode laser therapy on wound healing post gingivectomy
}

\author{
Esraa S. MAHMOUD ${ }^{1 \otimes M}$, Amal M. ABD EL-BAKY ${ }^{2}$, Osama M. SAID ${ }^{3}$ and Hussein G. HUSSEIN ${ }^{2}$ \\ ${ }^{1}$ Department of Physical Therapy for Surgery, Faculty of Physical Therapy, Badr University in Cairo "BUC", Egypt. \\ ${ }^{2}$ Department of Physical Therapy for Surgery, Faculty of Physical Therapy, Cairo University, Giza, Egypt. \\ ${ }^{3}$ Department of Periodontal Surgery, Faculty of dentistry, Badr University in Cairo "BUC", Egypt. \\ Corresponding author's Email: israa.sabry@buc.edu.eg; (D) ORCiD: 0000-0002-4738-9098
}

\begin{abstract}
Aim. The purpose of this study was to evaluate the effect of low-level diode laser therapy on wound healing after gingivectomy. Methods. Forty patients (male and female) with ages ranged from 20-40 years, and who received gingivectomy were participated in this study. They were selected randomly from dental outpatient clinic at Badr university in Cairo and randomly divided into two equal groups, including the study group (A) and control group (B). The study group (A) was irradiated with Gallium Arsenide (GaAs) laser of wavelength $850 \mathrm{~nm}$ for 4 sessions on day 0, 3, 7 and day 14 post gingivectomy, while the control group (B) received placebo laser. Assessment of healing was done before starting the first session (day 0), after session (days 7 and 14) and follow up on day 21 . The healing assessed by Landry index. Results. The results of this study supported that the low-level diode laser therapy was significantly effective $(p<0.001)$ on wound healing in patients after gingivectomy. Conclusion. It was concluded that the low-level diode laser therapy is an effective method for increasing wound healing after gingivectomy.
\end{abstract}

\author{
Original Article \\ PII: S225199392000010-10 \\ Rec. 14 September 2020 \\ Rev. 19 November 2020 \\ Pub. 25 November 2020
}

\author{
Keywords \\ Low level diode laser \\ therapy, \\ Wound healing, \\ Gingivectomy
}

\section{INTRODUCTION}

Gingival enlargement or hyperplasia is that the overgrowth of the gingiva characterized by an accumulation of the connective tissue with presence of increased number of cells [1]. Gingival enlargement affects patient's esthetics if present in the anterior maxillary or mandibular areas and leads to accumulation of plaque so gingival enlargement treated conventionally with Gingivoplasty or Gingivectomy operation. Gingivectomy is the removal of diseased gingiva and elimination of suprabony pocket. Gingivoplasty is the reshaping of the gingiva to create physiological contours to the gingiva in the absence of periodontal pockets [2].

Healing of gingivectomy wound is known to take by secondary intention and it takes about 4 weeks for complete epithelialization and about 7 weeks for connective tissue maturation [3]. Wound-healing process after scalpel gingivectomy is a slow phenomenon and the scalpel gingivectomy method can be performed either using gingivectomy knives (e.g., Kirkland knife and Orbans knife) or using surgical blades [4]. Low level laser therapy (LLLT) is represented by using the light for improving tissue healing, decreasing tissue inflammation, and controlling the pain [5]. Diode laser are most commonly used lasers in dentistry and the most commonly used wavelengths are 810 and $980 \mathrm{~nm}$ [6].

This study aimed to evaluate the effect of low-level diode laser therapy on wound healing after gingivectomy.

\section{MATERIAL AND METHODS}

This study was cross-sectional included 40 patients; the dentist referred them from dental outpatient clinic at Badr university in Cairo after receiving Gingivectomy in the maxillary and mandibular anterior region. Their ages ranged from 20 to 40 years and committed to maintain oral hygiene. They were free from any systemic diseases including diabetes, immune system deficiency, etc. The pregnant women, smokers, patients with a clear nutrition disorder and the degree of gingival inflammation was recorded by gingival index if it exceeded $l_{\text {, }}$ they were excluded from the study. Every patient applied informed consent before starting the study. 


\section{Ethical approval}

The Ethical Committee of the faculty of physical therapy (Cairo University. Egypt) approved the protocol of this study (No: P.T.REC/012/002713).

\section{Methods}

The wound healing was assessed by Landry index that the healing index (HI) scores healing on the basis of redness, presence of granulation tissues, bleeding, suppuration, and epithelialization. A score of 1-5 was given with score 1 for very poor healing, 2 for poor healing, 3 for good healing, 4 for very good healing and 5 being excellent healing of the tissues. Higher is the score, better is the healing. This index scores the surgical wound based on the clinical examination [7] (Table 1). Wound was assessed immediately (before the first session), day 7 , day 14 (after the session) and follow-up on day 21 [8] (Figure 1). The study was conducted in physical therapy outpatient clinic at Badr university in Cairo from March to August 2020. The forty patients who received Gingivectomy were divided into two equal groups: study group (A) and control one (B). All patients were instructed to maintain oral hygiene. The Group A (study) patients were irradiated with low level diode laser therapy (GaAs) (Chattanooga, model 27841, USA) for 4 sessions on day O, day 3, day 7 and day 14 [9]. The therapist placed a cheek retractor in the patient mouth to retract the lips and cheeks. Patient was asked to wear goggles to protect his eye. Patient was irradiated with low level diode laser therapy with wavelength $850 \mathrm{~nm}$ and power of $200 \mathrm{mw}$ in continuous mode. A dose of $4 \mathrm{j} / \mathrm{cm}^{2}$ was delivered and the total time was determined in accordance with each patient wound size with laser probe applied perpendicular for scanning an area about 1 $\mathrm{cm}^{2}$ with non-contact method $10 \mathrm{~mm}$ away from the wound site [5].

The group B (control) patients were treated with placebo laser for 4 sessions on day 0, day 3, day 7 and day 14 as the therapist set the device parameters without turning it on to convince the patient with the credibility of the session [9].

\section{Statistical analysis}

Descriptive statistics and unpaired t-test were conducted for comparison of the mean age between groups. Chi-squared was carried out for comparison of sex distribution between groups. ANOVA with repeated measures was conducted for comparison of wound surface area between day $0,7,14$, and 21 in each group and Friedman test was carried out for comparison of Landry index between day 0, 7, 14, and 21 in each group and was followed by Wilcoxon Signed Ranks for pairwise comparison. Unpaired t test for comparison of wound surface area between groups. Mann-Whitney U test was conducted for comparison of median values of Landry index between groups. The level of significance for all statistical tests was set at $\mathrm{p}<0.05$. All statistical analysis was conducted through the statistical package for social studies (SPSS) version 25 for windows (IBM SPSS, Chicago, IL, USA).

Table 1. Landry index for soft tissue healing [8].

\begin{tabular}{ll}
\hline Healing Grade & Clinical Criteria \\
\hline \multirow{3}{*}{ Very poor } & Tissue color: > 50\% of gingiva red. \\
& Response to palpation: bleeding. \\
& Granulation tissue: present. \\
& Incision margin: not epithelialized, with loss of epithelium beyond margins. \\
& Suppuration: present. \\
& Tissue color: $>50 \%$ of gingiva red. \\
Poor & Response to palpation: bleeding. \\
2 & Granulation tissue: present. \\
& Incision margin: not epithelialized, with connective tissue exposed. \\
Good & Response to palpation: no bleeding. \\
3 & Granulation tissue: none. \\
& Incision margin: no connective tissue exposed. \\
Very good & Tissue color: $<25 \%$ of gingiva red. \\
4 & Response to palpation: no bleeding. \\
& Granulation tissue: none. \\
Incision margin: no connective tissue exposed. \\
Excellent & Tissue color: all gingiva pink. \\
5 & Response to palpation: no bleeding. \\
& Granulation tissue: none. \\
& Incision margin: no connective tissue exposed.
\end{tabular}



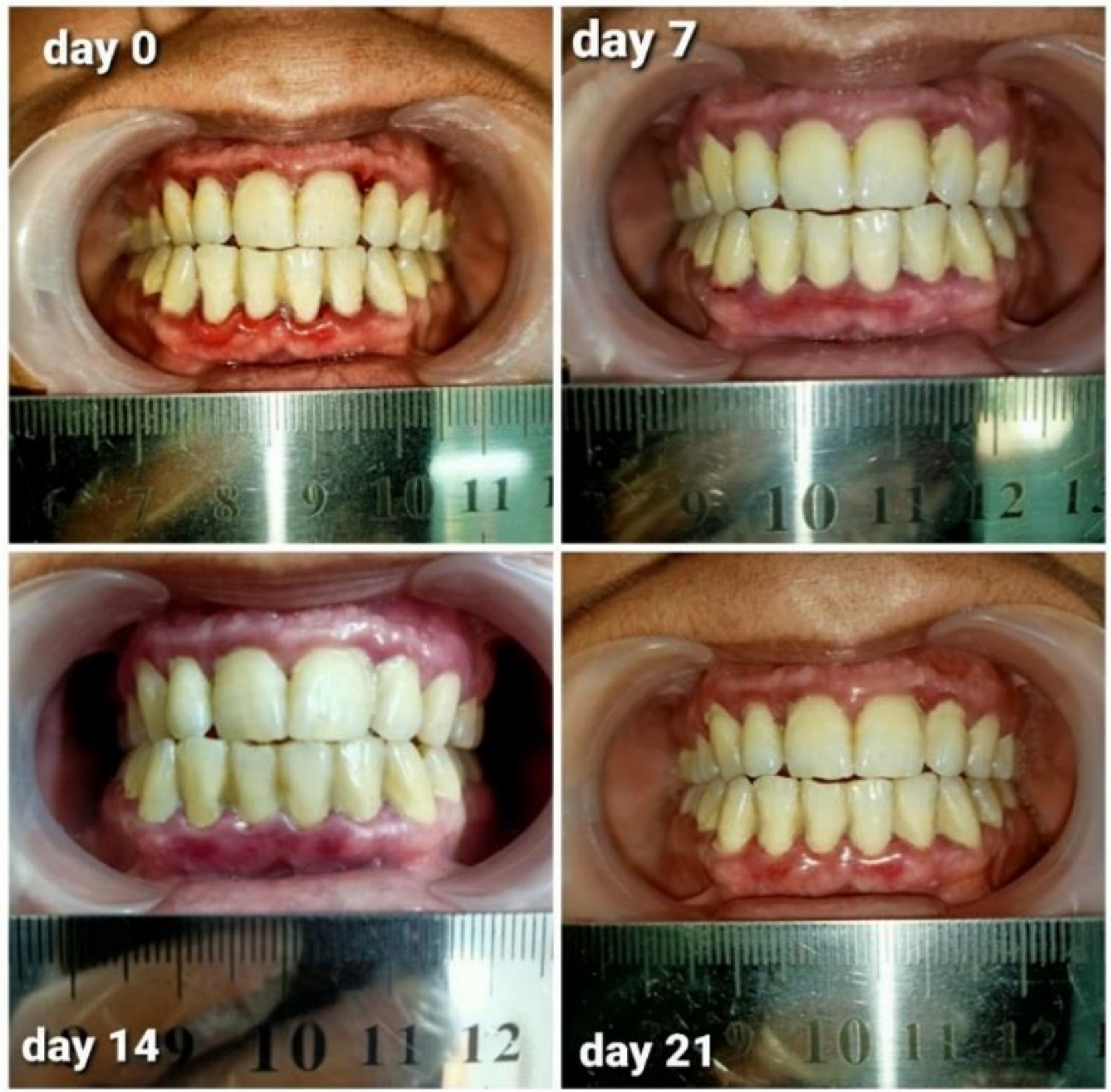

Figure 1. Wound healing by time from day o to day 21 on control group.

\section{RESULTS}

\section{Subject characteristics}

There was no significant difference between groups in age and sex distribution $(p>0.05)$. The mean \pm SD age of the study group was $30.55 \pm 7.76$ years and the mean \pm SD age of the control group was $29.5 \pm 5.5$ years. The sex distribution of the study group revealed that there were 15 females (75\%) while the number of males was $5(25 \%)$ and the sex distribution of the control group revealed that there were 13 females (65\%) while the number of males was 7 (35\%).

\section{Effect of treatment on wound surface area and Landry index}

Between group comparison. There was no significant difference in median value of Landry index between the study and control groups at day $\mathrm{O}(\mathrm{p}=1)$. There was a significant increase in the median value of Landry index of the study group at day 7, 14 and 21 compared with that of the control group ( $<<0.001$; Table 2).

Within group comparison. There was a significant increase in median value of Landry index of the study group at day 7, 14 and 21 compared with day $0(\mathrm{p}<0.001)$, a significant increase in Landry index at day 14 compared with day $7(\mathrm{p}<0.002)$ in day 21 compared with day $7(\mathrm{p}<0.001)$ and a significant increase in Landry 
index at day 21 compared with day 14 ( $<$ < 0.05). While in the control group there was a significant increase in median value of Landry index at day 7, 14 and 21 compared with day 0 ( $p<0.001)$, no significant difference in Landry index between day 7 and 14 ( $>$ > 0.05) and a significant increase in Landry index at day 21 compared with day 7 and 14 ( $\mathrm{p}<0.001$; Table 3$)$.

Table 2. Median Landry index at day 0, 7, 14 and 21 of the study and control groups.

\begin{tabular}{lcccc}
\hline Landry index & $\begin{array}{c}\text { Day o } \\
\text { Median (IQR) }\end{array}$ & $\begin{array}{c}\text { Day 7 } \\
\text { Median (IQR) }\end{array}$ & $\begin{array}{c}\text { Day 14 } \\
\text { Median (IQR) }\end{array}$ & $\begin{array}{c}\text { Day 21 } \\
\text { Median (IQR) }\end{array}$ \\
\hline Study group & $2(2,2)$ & $4(4.75,4)$ & $5(5,4)$ & $5(5,5)$ \\
Control group & $2(2,2)$ & $3(3,3)$ & $3(4,3)$ & $4(3,3)$ \\
U-value & 200 & 22.5 & 25 & 40 \\
P-value & $\mathrm{p}>0.05$ & $\mathrm{p}<0.001$ & $\mathrm{p}<0.001$ & $\mathrm{p}<0.001$ \\
\hline
\end{tabular}

IQR: Interquartile range; U-value: Mann-Whitney test value; $P$-value: level of significance.

Table 3. Comparison of Landry index between day 0, 7, 14 and 21 with in the study and control groups.

\begin{tabular}{lcccc}
\hline \multirow{2}{*}{ Days } & \multicolumn{2}{c}{ Study group } & \multicolumn{2}{c}{ Control group } \\
& Z-value & P-value & Z-value & P-value \\
\hline Day 0- Day 7 & 4.13 & 0.001 & 4.23 & 0.001 \\
Day 0- Day 14 & 4.13 & 0.001 & 4.09 & 0.001 \\
Day 0- Day 21 & 4.47 & 0.001 & 3.99 & 0.001 \\
Day 7- Day 14 & 3.16 & 0.002 & 1.63 & 0.1 \\
Day 7- Day 21 & 3.87 & 0.001 & 3.41 & 0.001 \\
Day 14- Day 21 & 2.23 & 0.02 & 3.31 & 0.001 \\
\hline
\end{tabular}

Z-value: Wilcoxon Signed Ranks Test value; P-value: level of significance.

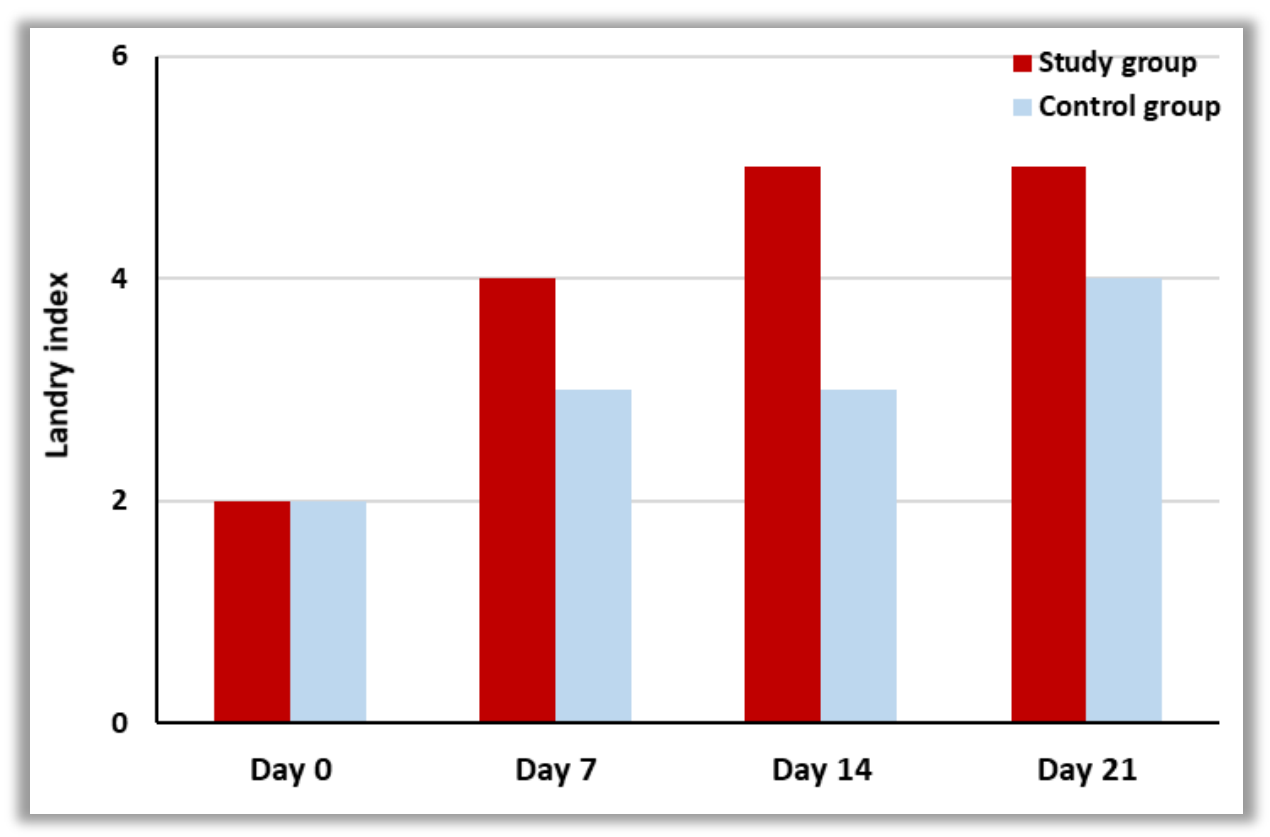

Figure 2. Median Landry index at day $0,7,14$ and 21 of the study and control groups.

\section{DISCUSSION}

The aim of the study was to evaluate the effect of low-level diode laser therapy on wound healing post gingivectomy. The results of this study support that the low-level diode laser therapy was significantly effective on wound healing in patients post gingivectomy more than the medical treatment. There was a highly significant difference between two groups after the treatment.

The result of the present study agreed with Faria et al. [10] reported that the laser-treated group had a faster recovery post gingivectomy and reduction of pocket depth compared to control group. Twenty patients irradiated with LLLT immediately post-surgery, $24 \mathrm{~h}, 3^{\text {rd }}$ day and $7^{\text {th }}$ day. The difference between this study and 
the present study depended on laser parameters but both supported that LLLT had beneficial effect on wound healing after gingivectomy operation. The wavelength is an important parameter to evaluate laser effectiveness. In this study the wavelength was $685 \mathrm{~nm}$, while in the present study was $850 \mathrm{~nm}$. The power used in this study was $50 \mathrm{mw}$ applied in a contact with the wound for 4 sessions on day 0 , 24h, day 3 and day 7 . On the other hand, the power in the present study was $200 \mathrm{mw}$ in a non-contact method $10 \mathrm{~mm}$ away from the wound site for 4 sessions on day 0 , day 3, day 7 and day 14. The irradiated wounds underwent a better healing process than the wounds from the control group, because of higher collagen production leading to a better remodeling of the connective tissue and a reduction of the probing depth. The reduction of the probing depth in the early stages of healing is as very positive finding.

Also, the result of the present study agreed with Kohale et al. [11] conducted a study to assess the effect of LLLT on wound healing and patient's response after scalpel gingivectomy and results indicated that LLLT improved wound healing. Forty patients involved in the study, received laser therapy on day o, day3 and day7 and healing assessed on day 3, day 7 and 1 month after surgery. The difference between this study and the present study was based on laser parameters but both accelerate wound healing of the gingiva after gingivectomy. In this study, although the power and the repetition of the laser were less than in the present study as the power was $100 \mathrm{mw}$ and it had beneficial effect of the healing due to the large wavelength that was $940 \mathrm{~nm}$. As the penetration depth increases with increasing wavelength [12]. The study explained that the effectiveness of wound healing after LLLT as there were formation and proliferation of newer blood vessels and fibroblasts in the initial stages of wound healing. LLLT reduce inflammation by lowering the levels of prostaglandin E2, interleukin-1 beta, tumor necrosis factor alpha, cellular influx of neutrophils and granulocytes, oxidative stress, edema, and bleeding.

Also, Reddy et al. [13] compared the efficacy of low-level laser therapy, hyaluronic acid and herbal gel when used topically after a gingivectomy. They reported that there were statistically significant results observed in the low-level laser therapy group on wound healing more than hyaluronic acid and herbal gel groups. In this study 10 subjects received laser on day 1 , day 3 and day 7 post surgery. However, laser power of this study was $50 \mathrm{mw}$ for 3 min only with contact method, the LLLT group showed better results due to the large wavelength as it was $980 \mathrm{~nm}$. On the other hand, the power in the present study was $200 \mathrm{mw}$ in a non-contact method with $10 \mathrm{~mm}$ away from the wound site. The study explained that LLLT applied to soft tissues excited specific metabolic processes in healing wounds. The major changes observed include increased granulation tissue, early epithelialization, increased fibroblast proliferation, and matrix synthesis. Also, the histological evaluation showed more mature collagen fibers in the laser group.

Only few studies reported that low level diode laser therapy has not affect wound healing in patients post gingivectomy that observed and recorded by Damante et al. [14] reported that low-level laser therapy did not accelerate the healing of oral mucosa after gingivoplasty. The first difference between this study and the present study was the small sample size as 16 patients in the study with both sides gingivoplasty and one side used as control so that could affect negatively the results and might make a type of error. The second difference was the wavelength $670 \mathrm{~nm}$ while wavelength of the present study was $850 \mathrm{~nm}$ and the penetration depth increase with increasing wavelength [12]. The third one was the power used in this study $15 \mathrm{mw}$ it was very small because penetration and absorption of laser light can also be affected by the power output, the greater the number of photons which penetrate the tissue at any time, the greater the number of photons will be present at any given depth and higher power densities with shorter irradiation times might be more efficient in the delivery of LLLT [15], while the power of the present study was $200 \mathrm{mw}$. The forth one was sessions interval in this study the laser was applied $48 \mathrm{~h}$ for 1 week for a total of 4 sessions while the laser applied in the present study was applied for 2 weeks on day 0, day 3, day 7 and day 14, repeated irradiation increased the proliferation of fibroblasts [16]. The fifth and last difference was the healing assessed in this study after gingivoplasty and it was a simple surgical procedure, it had excellent post-operative outcome in most cases and healing was a very rapid process while the present study assessed the wound healing after gingivoplasty and gingivectomy operations which is more complex than gingivoplasty alone.

Also, the present study was disagreed with Hammadi and Ahmed [17] reported that low-level laser therapy did not accelerate oral mucosa healing after gingivectomy. The first difference between this study and the present study was the small sample size as 11 patients in the study with both sides gingivectomy so that might impair the results while in the present study 40 patients. The second one was sessions interval in this study the laser was applied $48 \mathrm{~h}$ for 1 week for a total of 4 sessions while the laser applied in the present study was for 2 weeks on day 0, day 3, day 7 and day 14, repeated irradiation increased the proliferation of fibroblasts. The other 
differences were due to parameters of the LLLT used in the study, the wavelength of the laser therapy used in this study was $670 \mathrm{~nm}$ while the wavelength of the present study was $850 \mathrm{~nm}$ as the penetration depth increases with increasing wavelength. In this study they used contact method of the laser head with the wound that might be a source of infection for the wound site while in the present study the laser probe applied perpendicular in a non-contact method $10 \mathrm{~mm}$ away from the wound site. There was a lack of parameters of the low-level laser application in this study as they weren't discussed the amount of power and the application mode used in the study that could alter the results.

Our study was limited by many factors such as small sample size, physical and psychological conditions of the patients during the period of the treatment, possible human error's application of measurement or therapeutic procedure, cooperation of the patient and maintenance of oral hygiene.

In the present study there was acceleration of wound healing by using low level diode laser therapy after gingivectomy by using these parameters and it is explained by that LLLT decreased bleeding after surgery and formed protective surface clot by acceleration of the hemostasis phase then promoted the granulation tissue to replace the surface clot. It accelerated the inflammatory phase by increasing the level of growth factors and cytokines, which are important to improve cell proliferation and migration. Fibroblasts migrate into the wound site from the surrounding tissue and endothelial cells proliferate from intact venules close to the wound and form new capillaries by the process of angiogenesis, so it increased the new connective tissue formation. And the migrated fibroblasts improved collagen formation and made a better organization for the gingival tissue. Finally, LLLT accelerated covering the wound and the injured gingiva became as pink as the normal gingiva [18].

\section{CONCLUSION}

It was concluded that the low-level diode laser therapy is an effective method for accelerating wound healing after gingivectomy surgery. Further studies are needed to examine the effect of low-level laser therapy on wound healing after gingivectomy, but supra-bony periodontal pockets must be determined before surgery. And further well-designed controlled trials with larger sample sizes comparing various irradiation regimens are needed to find the optimal parameters of LLLT after periodontal surgeries.

\section{DECLARATIONS}

\section{Authors' contributions}

Esraa S. Mahmoud was concerned with the research design, writing the article and data collection. Amal M. Abd El-baky provided valuable contributions to planning stages of the study and gave approval for publication of the study, Osama M. Said took responsibility of the referred patients and Hussein G. Hussein made significant contribution for data analysis and interpretation.

\section{Conflict of interest}

The authors declare that there is no conflict of interest.

\section{REFERENCES}

1. Agrawal AA. Gingival enlargements: Differential diagnosis and review of literature. World Journal of Clinical Cases: WJCC. 2015 Sep 16; 3(9):779. https://dx.doi.org/10.12998\%2Fwjcc.v3.ig.779 ; Google Scholar

2. Shankar BS, Ramadevi T, Neetha MS, Reddy PS, Saritha G, Reddy JM. Chronic inflammatory gingival overgrowths: laser gingivectomy \& gingivoplasty. Journal of international oral health: JIOH. 2013 Feb; 5(1):83. PMID: 24155582 ; Google Scholar

3. Zhao $\mathrm{H}, \mathrm{Hu}$ J, Zhao L. The effect of low-level laser therapy as an adjunct to periodontal surgery in the management of postoperative pain and wound healing: a systematic review and meta-analysis. Lasers in Medical Science. 2021 Feb; 36(1):175-87 https://doi.org/10.1007/s10103-020-03072-5 ; Google Scholar

4. Perry DA, Newman MG, Takei HH, Klokkevold FR. Carranza's clinical periodontology. Influence of Systemic Conditions on the Periodontium. 2012:304-19. Google Scholar

5. Carroll JD, Milward MR, Cooper PR, Hadis M, Palin WM. Developments in low level light therapy (LLLT) for dentistry. Dental Materials. 2014 May 1; 30(5):465-75. https://doi.org/10.1016/j.dental.2014.02.006 ; Google Scholar 
6. Hitz CB, Ewing JJ, Hecht J. Introduction to laser technology. John Wiley \& Sons; 2012 Apr 2. Google Scholar

7. Landry RG. Effectiveness of benzydamine $\mathrm{HCl}$ in the treatment of periodontal post-surgical patients (Doctoral dissertation, Faculty of Dentistry, University of Toronto). ; Google Scholar

8. Lingamaneni S, Mandadi LR, Pathakota KR. Assessment of healing following low-level laser irradiation after gingivectomy operations using a novel soft tissue healing index: A randomized, double-blind, split-mouth clinical pilot study. Journal of Indian Society of Periodontology. 2019 Jan; 23(1):53. https://dx.doi.org/10.4103\%2Fjisp.jisp 226 18 ; PMID: 30692744 ; Google Scholar

9. Saxena S, Govila V, Verma S, Dubey DM, Srivastava V, Sinha SS. The effects of low level laser therapy on healing of gingiva after gingivectomy. University Journal of Dental Sciences. 2019 Oct 28;5(2):39-46. Direct link ; Google Scholar

10. Faria Amorim JC, Sousa GR, Silveira LD, Prates RA, Pinotti M, Ribeiro MS. Clinical study of the gingiva healing after gingivectomy and low-level laser therapy. Photomedicine and Laser Therapy. 2006 Oct 1;24(5):588-94. https://doi.org/10.1089/pho.2006.24.588; Google Scholar

11. Kohale BR, Agrawal AA, Raut CP. Effect of low-level laser therapy on wound healing and patients' response after scalpel gingivectomy: A randomized clinical split-mouth study. Journal of Indian Society of Periodontology. 2018 Sep;22(5):419. https://dx.doi.org/10.4103\%2Fjisp.jisp 239 18 ; PMID: 30210191 ; Google Scholar

12. Ash C, Dubec M, Donne $\mathrm{K}$, Bashford $\mathrm{T}$. Effect of wavelength and beam width on penetration in light-tissue interaction using computational methods. Lasers in medical science. 2017 Nov;32(8):1909-18. https://doi.org/10.1007/s10103-0172317-4; Google Scholar

13. Reddy SP, Koduganti RR, Panthula VR, Prasanna JS, Gireddy H, Dasari R, Ambati M. Efficacy of low-level laser therapy, hyaluronic acid gel, and herbal gel as adjunctive tools in gingivectomy wound healing: a randomized comparative clinical and histological study. Cureus. 2019 Dec;11(12). https://dx.doi.org/10.7759\%2Fcureus.6438 ; PMID: 31993275 ; Google Scholar

14. Damante CA, Greghi SL, Sant'Ana AC, Passanezi E, Taga R. Histomorphometric study of the healing of human oral mucosa after gingivoplasty and low-level laser therapy. Lasers in Surgery and Medicine: The Official Journal of the American Society for Laser Medicine and Surgery. 2004 Dec; 35(5):377-84. https://doi.org/10.1002/lsm.20111 ; Google $\underline{\text { Scholar }}$

15. Laakso L, Richardson C, Cramond T. Factors affecting low level laser therapy. Australian Journal of Physiotherapy. 1993 Jan 1; 39(2):95-9. https://doi.org/10.1016/So004-9514(14)60473-6 ; Google Scholar

16. Skinner SM, Gage JP, Wilce PA, Shaw RM. A preliminary study of the effects of laser radiation on collagen metabolism in cell culture. Australian dental journal. 1996 Jun; 41(3):188-92. https://doi.org/10.1111/j.1834-7819.1996.tbo4854.x ; Google Scholar

17. Hammadi AA, Unit L. Clinical assessment of low level laser (gaalas) on gingivectomy wound healing. Medical Journal of Babylon. 2013; 10(2): 349-353. Google Scholar

18. Carranza FA. The gingivectomy technique. Newman MG, Takei HH, Carranza FA. Carranza's Clinical Periodontology. gth ed. WB Saunders Co. 2002. Google Scholar 